\title{
LA MEMORIA LITERARIA. MECANISMOS ALEGÓRICOS Y COGNITIVOS EN LA CUENTÍSTICA MEDIEVAL (DEL EXEMPLUM $A L$ CONDE LUCANOR)
}

\author{
Juan PAREDES \\ Universidad de Granada \\ jparedes@ugr.es
}

\section{La memoria literaria}

«Nessun maggior dolore / che ricordarsi del tempo felice / nella miseria», dice Francesca de Rímini a Dante que, en su viaje por los reinos de ultratumba, en el círculo segundo del Infierno, adonde van los espíritus lujuriosos, encuentra a la inmortal pareja de amantes que el amor condenó al mismo destino del sufrimiento eterno y a la que pregunta por la causa primigenia que originó su mal. La respuesta es todo un tributo a la memoria literaria, no sólo por las implicaciones del texto en el texto, con el recuerdo, tangible por la presencia del propio texto literario, del episodio del primer beso de la reina Ginebra a Lanzarote, sino por la referencia directa a una memoria que, en este caso concreto, no quiere conceder el regalo del olvido. El tiempo presente, instaurado en el texto de Dante, retrotrae el recuerdo de un pasado que se instala en otro texto literario, el Lanzarote en prosa, que a su vez explica y justifica al primero. Existen, por lo tanto, dos tiempos, el de la lectura, cuando los amantes caen subyugados por la presencia literaria de otros amantes, también de ficción, y el de la historia, actualizada en un presente eterno por la memoria, que es la que realmente recrea el pasado y el transcurso del tiempo. La seducción literaria del texto primigenio desencadena el destino fatal de los amantes, condenados a girar eternamente en la borrasca infernal entre las sombras que el amor arrebató a la vida. El mísero presente no quiere relegar al olvido el tiempo feliz, cuyo recuerdo es el que va a determinar en realidad el dolor de la condena eterna. 
En uno de los exempla recogidos en los Sermones aurei de Jacobo de Voragine $^{1}$ se pregunta al filósofo Simónides de Ceos qué es lo que envejece más fácilmente entre los hombres, y él responde que la buena acción que es rápidamente olvidada. Aquí es, por el contrario, el olvido del momento feliz, que en el pasaje de Dante se niega a los amantes para su sufrimiento eterno, el que determina la acción negativa del envejecimiento. La función de la memoria, que en el primer caso actúa como desencadenante del castigo, perenne precisamente porque se mantiene viva de manera inexorable, cumple en el exemplum un papel totalmente diferente en cuanto que es su pérdida la que desencadena la punición.

\section{El exemplum. Mecanismos alegóricos}

La alegorización es la coadyuvante necesaria para que la memoria cumpla su función ejemplar. Así ocurre en otros exempla de la misma colección donde el recuerdo de la muerte ahuyenta los malos pensamientos, igual que la cola de los animales espanta a las moscas²; o se compara, por oposición, a los hombres, caracterizados por el olvido, la jerarquía y la falta de compasión, con Dios, fuente de amor maternal, memoria perpetua, solicitud asidua y humildad ${ }^{3}$. El Espíritu Santo lava el corazón de los hombres, para limpiar sus pecados, con el agua de sus propias lágrimas y las cenizas de la memoria de la muerte ${ }^{4}$ Y en el alma hay tres casas: la memoria, la inteligencia y la voluntad $^{5}$. De la misma manera que el diamante resiste al fuego y al martillo y solo puede ser cortado rociándolo con sangre de macho cabrío, los pecadores empedernidos sólo pueden ser ablandados por la memoria de la Pasión de Cristo ${ }^{6}$. Después de su muerte, Ariosto se aparece a un discípulo y le dice que él ha olvidado toda su ciencia y que ya no se ocupa más que de los castigos que debe soportar ${ }^{7}$. En otro de los exempla transmitidos por la Vita Patrum $^{8}$, la imagen del Juicio Final es utilizada para dejar en la memoria de los pecadores la confusión que podrían experimentar en presencia de Dios,

\footnotetext{
${ }^{1}$ Jacobus de Voragine, Sermones aurei, ed. de Clutius, Paris, 1760, t. I, p. 304a, De tempore, Schneyer, Geschichte der Katholischen Predigt, Friburg, 1964, T39.

${ }^{2}$ Jacobus de Voragine, Sermones aurei, ed. de Figarol, Toulouse, 1874, t. I, p. 7. In die cinerum, Sermo I.

${ }^{3}$ Ibidem, t. I, pp. 474-475. Feria post Pascha, Sermo II.

${ }^{4}$ Ibidem, t. I, p. 213. Feria sexta tertiae hebdomadae quadragesimae, Sermo II.

${ }^{5}$ Ibidem, t. I, p. 161. Domenica tertiae hebdomadae quadragesimae, Sermo I.

${ }^{6}$ Jacobus de Voragine, Sermones aurei, ed. de Clutius, t. II, p. 134b, De sanctis. Schneyer, 408.

${ }^{7}$ Ibidem, t. I, De tempore, p. 29. Domenica XXIV post Trinitat. Sermo III.

${ }^{8} \mathrm{Vid}$. Stephanus de Borbon, Tratatus de diversis materiis praedicabilibus, ed. de Berlioz, Turnhout, Brepols, 2002, p. 231. Tubach, Index Exemplorum, Helsinki, 1969, FF Communications, 204, 4161.
} 
Cristo, los ángeles y arcángeles y de todos los hombres. Ci nous $d i t^{9}$ recoge también diversos ejemplos en los que la memoria es utilizada como proceso de alegorización. En "El hijo del rey que esposó a una dama viuda"10, la noble dama viuda es nuestra santa madre Iglesia, el hijo del rey es Jesucristo, que ha venido a salvarla por medio de su Pasión y muerte, y el escudo de plata cartelado de azul con cinco rosetas de gules, símbolos de la crucifixión, que representan los golpes recibidos con las marcas que dejaron y las cinco crueles llagas que deben quedar para siempre gravadas en la memoria y en el corazón de los verdaderos creyentes ${ }^{11}$. Del tiempo de la historia, uno de tantos relatos sobre vasallos rebeldes que intentan desposeer de su feudo a una dama viuda, nos retrotraemos al tiempo evangélico, de donde surge la alegoría, que es donde se instala el tiempo de la memoria.

\section{El exemplum. Mecanismos cognitivos}

Pero también la memoria actúa como mecanismo cognitivo, convirtiéndose en medio de aprendizaje y ejemplificación. Destaca, entre los diversos motivos, particularmente el empleo del arte de la memoria como medio mnemotécnico para recordar la plegaria. Así, en uno de los ejemplos de la predicación de Bernardino de Siena ${ }^{12}$ se cuenta cómo para enseñar el Pater Noster a uno de sus feligreses que era usurero y no sabía leer ni escribir, un cura rural envió a veinte pobres para que le compraran grano a crédito, dando a cada uno de ellos como nombre una parte del Padrenuestro. De esta manera, el usurero, al memorizar sus nombres, aprendió la plegaria sin darse cuenta. El relato, muy ligado a la tradición oral, pone de manifiesto los resortes del ars praedicandi, y el uso de la memoria como sistema de aprendizaje ${ }^{13}$. En otro de los relatos es el propio San Francisco quien llamado a predicar ante el Papa y los cardenales, memoriza el texto, por sugerencia del cardenal de Ostia y de acuerdo con las normas del arte de la predicación. En el momento de pronunciarlo lo olvida y tiene que improvisar un nuevo sermón mucho más emotivo al venir directamente del corazón ${ }^{14}$. Ligado también al poder de

\footnotetext{
${ }^{9}$ Ci nous dit. Recueil d'exemples moraux, ed. de G. Blangez, Paris, SATF, 1979-1986, 2 vols.

${ }^{10}$ Ci nous dit, ed. cit., 1-20. Tubach, 204, 338, 4020, 4585.

${ }^{11}$ Marie Anne Polo de Beaulieu, «L'inscription du miracle dans le corps du saint: le coeur inscrit d'Ignace d'Antioche à Claire de Montefaco», en Miracle et Karama. Hagiographies médiévales comparées, ed. de Denise Aigle, Turnhout, Brepols, 2000, pp. 217-236.

${ }^{12}$ S. Bernardino de Siena, Le prediche volgari, ed. de P. C. Cannarozzi, 1934, II, pp. 91-93.

${ }^{13}$ C. Delcorno, «L'ars praedicandi di Bernardino da Siena», en Atti del Simposio Internazionale cateriniano-bernardiniano, Siena, 17-20 aprile 1980, ed. de D. Maffei y P. Nardi, Siena, Accademia Senese degli Intronati, 1982, p. 430.

${ }^{14}$ Bernardino da Siena, Prediche volgari sul Campo di Siena 1427, ed. de Delcorno, Milano, 1989, 
la predicación y la memoria está otro ejemplo ${ }^{15}$, también recogido en la Vitae Patrum $^{16}$, de donde sin duda procede, en el que un aprendiz de ermitaño no va nunca a escuchar el sermón, con la excusa de que es incapaz de recordar nada de lo escuchado. Su maestro le dice que de la misma manera que el agua hirviendo limpia poco a poco la sartén grasienta, la palabra de Dios purifica el alma, aunque no pueda ser recordada.

Numerosos son los ejemplos en los que la memoria aparece directamente vinculada a la oración. En las mismas prediche volgari de Bernardino de Siena ${ }^{17}$ se relata cómo un hombre habituado a rezar el Ave María todos los días antes de dormir, olvida en una ocasión realizar su plegaria y no consigue conciliar el sueño. El relato, procedente sin duda de la tradición oral, está relacionado con la devoción mariana y la arraigada costumbre del rezo a la Virgen para que preserve el sueño y guarde de todos los peligros. En uno de los exempla del Libro de los exemplos por A.B.C., «Marie continua salutatio diaboli liberat ab insidis», el diablo, que como en tantos otros ejemplos, toma forma de hombre, no puede conseguir su propósito de llevarse el alma de un caballero por su devoción a la Virgen:

¡Ay, que soy conjurado! Yo no soy hombre, mas demonio que tomé figura de hombre e he morado con este cavallero catorze años, ca el príncipe nuestro me imbió aquí para que, el día que este non dixese la salutación a la sua María, que lo aguardasse bien. E diome poderío que luego lo afogasse e así acabaría su vida en malas obras e sería nuestro. E por cuanto cada día dezía aquella salutación, Ave María, non pude haver poderío en él, e de día en día aguardándolo con gran deligençia nunca fue día que la dexasse de dezir ${ }^{18}$.

Como reza el refrán del exemplum «Maria eciam peccantibus est adiutrix»: «A la Virgen deven dar muchos loores, / que libra e ayuda a los pecadores» ${ }^{19}$. En otro un anciano se bate con sus propios pensamientos. Había confiado a su memoria catorce obras, pero solo una palabra le viene a su espíritu en

pp. 1340-41. Vid. C. Delcorno, «Origini della predicazione francescana», en Francesco d'Assisi e francescanesimo dal 1216 al 1226. Atti del IV Convegno Internazionale, Assisi 15-17 ottobre 1976, Assisi, Società internazionale di studi francescani, 1977, p. 148. Tubach 2188 y 2196.

${ }^{15}$ Bernardino da Siena, ed. cit., pp. 196-97. Novellette, esempi morali e apologhi di San Bernardino da Siena, ed. de F. Zambrini, 1868, II, pp. 3-5. Tubach 3927.

${ }^{16}$ Vitae Patrum, V, 10, 92. Patrología latina, 73, col. 929.

${ }^{17}$ Bernardino da Siena, Le prediche volgari. Quaresimale del 1425, ed. de P. C. Cannarozzi, Pistoia, Tip. A. Paconotti e C., 1940, I, p. 97. Novellette, esempi morali e apologhi di San Bernardino da Siena, Bologna, Gaetano Romagnoli, 1868, II, pp. 3-5. Tubach 3891.

${ }^{18}$ Clemente Sánchez, Libro de los exemplos por A.B.C., ed. de Andrea Baldissera, Pisa, Edizioni ETS, 2005, p. 191.

${ }^{19}$ Ibidem, p. 194. 
plegaria, Había olvidado todas las demás ${ }^{20}$. Otro exemplum, recogido por Étienne de Bourbon, cuenta cómo un santo padre olvida decir nona y ve pasar delante de él al diablo, que lleva sobre sus espaldas un libro en forma de rollo tan grueso como una torre ${ }^{21}$. En la Leyenda Aurea el protagonista es San Agustín. Y son muy numerosos los exempla en los que la memoria aparece directamente relacionada con la confesión ${ }^{22}$.

\section{Mecanismos cognitivos en El conde Lucanor}

El recurso, ampliamente utilizado en todos estos relatos tan directamente vinculados a la homilética, alcanza también una enorme difusión en las colecciones de cuentos más directamente relacionadas con la función didáctica, donde los mecanismos cognitivos, siempre con una clara intención ejemplar, tienen una relevancia particular.

La obra prototípica, en este sentido, es sin duda El conde Lucanor, o Libro de los enxiemplos del conde Lucanor et de Patronio, donde la intención didáctica, translación del pensamiento y la propia doctrina del autor, sus preocupaciones religiosas, sociales, filosófico-morales y políticas ${ }^{23}$, determina la estructura y el sentido profundo del texto. Los cuentos, como ocurre en otras colecciones como la Disciplina clericalis o el Lucidario, se estructuran como diálogo narrativo, como una representación simulada del aprendizaje, con una clara finalidad didáctica. El mecanismo narrativo es siempre el mismo: El conde Lucanor pregunta a su ayo Patronio sobre un determinado tema a propósito del cual, y con un sentido estrictamente ejemplar, este relata un cuento: «El conde Lucanor le rogó quel dixiese cómmo fuera aquello». «-Señor-dixo Patronio-» $(20)^{24}$.

${ }^{20}$ Stephani de Borbone, Tractatus de diversis materiis predicabilibus, tertia pars, ed. de Jacques Berlioz, Turnhout, Brepols, 2006.

${ }^{21}$ A. Lecoy de la Marche, Anecdotes historiques, légendes et apologues, tirés du recueil inédit d'Etienne de Bourbon, dominicain du xIII siècle, Paris, 1877; Stephani de Borbone, ed. cit.; S. Thompson, Motif-Index of Folk-Literature. A classification of narrative elements in folktales, ballads, myths, fables, mediaeval romances, exempla, fabliaux, jest-books and local legends. Revised and enlarged edition..., London, Bloomington, 6 vols., 1975, G303.16.9, G303.24.1.1, V29.6; Tubach 378.

${ }^{22}$ Vid. J. Paredes, «E vio diablos que bolavan. Ángeles de luz y de tinieblas en el Libro de los exemplos por A.B.C. (Función y tipología)», en Formas narrativas breves. Lecturas e interpretaciones, San Millán de la Cogolla, Cilengua, 2014, pp. 265-282.

${ }^{23}$ Una estructura ternaria, determinada por los planos religioso, social y político que, como señala Fernando Gómez Redondo, se repite en la de cada exemplo, «en donde los personajes deben asumir los aspectos concretos de la existencia de su creador, para convertirlos en signos de intención didáctica» (Historia de la prosa medieval castellana. I. La creación del discurso prosístico: el entramado cortesano, Madrid, Cátedra, 1998, p.1155).

${ }^{24}$ Las citas corresponden a la ed. de Guillermo Serés, El conde Lucanor, Barcelona, Crítica, 2001. 
Al final se inserta una especie de recapitulación que sirve de engarce con el ejemplo siguiente: «Et veyendo don Johán que este exienplo era bueno, mandolo poner en este libro, et fizo estos viessos en que se entiende abreviadamente todo el enxienplo». «Et los viessos dizen assí:» (38).

El autor, cuya presencia es constante y de una manera casi obsesiva en toda la obra a través de sus personajes, aparece ahora de manera explícita al final de cada ejemplo para concretar su significado y resumirlo, de manera mnemotécnica, en los versos. Don Juan Manuel, autor, se convierte así en receptor, capaz de concentrar la enseñanza de cada ejemplo en unos versos, que a su vez entrega a otro receptor: el lector. El juego de realidad y ficción queda patente en cada uno de los ejemplos a través de tres niveles distintos de significación: el de la realidad del noble acuciado por una serie de conflictos sobre los que debe tomar una decisión, el de la ficción literaria del relato propiamente dicho, que supone un distanciamiento de la realidad, y por último el de la vuelta a la realidad, ya transformada por la enseñanza que se desprende del cuento ${ }^{25}$.

También en el Calila e Dimna Berzebuey, «que era físico conoscido, era sabio y filósofo», trasladó al lenguaje de Persia las escrituras que había encontrado en lugar de las yerbas y plantas de las que «se sacaría[n] melezinas con que resuçitasen los muertos», porque la «melezina» de que ellas hablaban «son los buenos castigos et del saber», y los muertos que resucitaban «los omnes necios que non saben quándo son melezinados en el saber [...] et luego, en leyendo, aprenden el saber et alumbran sus entendimientos», y se volvió a su señor, el rey Sirechuel, quien mandó, para que no se perdiera memoria de estos escritos, que el pueblo los leyese, y rogase a Dios le concediese la gracia de que fueran entendidos:

Et este rey era muy acuçioso en allegar el saber et en amar los filósofos más que a otri, et trabajávase en aprender el saber, et amávalo más que a muchos deleites en que los reyes se entremeten. Et quando fue Berzebuey en su tierra, mandó a todo el pueblo que tomasen aquellos escriptos, et que los leyesen et rogasen a Dios que les diese graçia con que los entendiesen; et dioles aquellos que eran más privados en la casa del rey. Et el uno de aquellos escriptos es aqueste libro de Calila e Dina ${ }^{26}$.

En El conde Lucanor encontramos, tras los «viessos», la formulación más controvertida: «Et la estoria deste exienplo es esta que sigue» (38). Términos que en su expresión concreta han dado lugar a interpretaciones diferentes,

${ }^{25}$ Ibidem, pp.1156-1158.

${ }^{26}$ Calila e Dimna, ed. de Juan Manuel Cacho Blecua y María Jesús Lacarra, Madrid, Castalia, 1988. 
todas ellas encaminadas a determinar su exacto significado y con ello la misma estructura de la obra y la forma de engarce de los relatos. María Rosa Lida supone que «exiemplo» significaría la unidad general, mientras que la «estoria» sería la parte narrativa, y los «viessos» el núcleo didáctico ${ }^{27}$. José Manuel Blecua, por su parte, propone una interpretación distinta, basándose en el significado, ampliamente documentado, del término «estoria» como «pintura» $\mathrm{y}$ «dibujo» ${ }^{28}$; podría tratarse de una miniatura que siguiera al cuento en el códice original. El espacio en blanco entre cuento y cuento en el manuscrito parecería apoyar esta hipótesis. La gran cantidad de iletrados de esta época obligaba sin duda a recurrir, como también hacen los clérigos con la iconografía, a todos estos artilugios plásticos. Y no hay que olvidar que la ilustración es uno de los medios más eficaces para incentivar el pensamiento y conservar en la memoria un mensaje concreto o una enseñanza. Los tratados de pedagogía abundan en preceptos en este sentido.

El propio Don Juan Manuel, cada vez más consciente de la importancia del sistema compositivo de su obra se va a encargar de justificar la técnica narrativa empleada, con «semejanças» y «palabras falagueras» -porque «todos usan et quieren et aprenden mejor aquellas cosas de que se más pagan que las otras»-, es decir, es más fácil retenerlas en la memoria, para que «los omnes fiziessen en este mundo tales obras que les fuessen aprovechosas de las onras et de las faziendas et de sus estados, et fuessen más allegados a la carrera por que pudiessen salvar las almas» (11):

Et porque los omnes non pueden tan bien (entender) las cosas por otra manera commo por algunas semejanças, conpus este libro en manera de preguntas et respuestas que fazian entre si un rrey et un infante su fijo, et un cavallero que crio al infante, et un philosofo ${ }^{29}$.

\footnotetext{
${ }^{27}$ «Tres notas sobre don Juan Manuel», en Estudios de literatura española comparada, Buenos Aires, 1966, pp. 101-102.

${ }^{28}$ Don Juan Manuel. El conde Lucanor, ed. de José Manuel Blecua, Madrid, Castalia, 1969. Los testimonios son numerosos. Sin necesidad de salir de la misma obra, en el ejemplo XXXII aparece el término con esta significación: «Et quando entró en el palacio et vio los maestros que estaban texiendo et dizían: 'Esto es tal labor, et esto es tal ystoria, et esto es tal figura, et esto tal color» (p. 180). Según Zumthor (Essai de poétique médiévale, Paris, Editions du Seuil, 1972, p. 348), en los vocabularios franceses de los siglos XII y XIII, e incluso más tarde, el término estoire, que también es utilizado con el significado de «peinture» e «illustration», es intercambiable con roman. Vid. sobre el tema Jules Piccus, «The Meaning of "Estoria" in Juan Manuel's El Conde Lucanor», en Hispania, 61 (1978), pp. 459-465; Francisco Marcos-Marín, «Estoria como "representación secuencial": nota sobre el Libro de buen amor, desde Alfonso X, el Libro de Alexandre, el Conde Lucanor y otras referencias», en Archivum, 27-28 (1977-1978), pp. 523-528.

${ }^{29}$ Don Juan Manuel, Libro de los estados, ed. de R. B. Tate y I. R. Macpheron, Oxford, Clarendon Press, 1974, p. 16.
} 
Y el método de presentación de la enseñanza a través de ejemplos y comparaciones:

«Otrossi, sennor infante, devedes saber que por rrazón que los omnes somos enbueltos en esta carnalidat grasosa non podemos entender las cosas sotiles spirituales sinon por algunas semejanças» $»^{30}$.

La función didáctica del marco se articula en dos planos. Está por un lado el plano diegético del relato propiamente dicho, el cuento; y por otro, externo al cuento pero interno al enxemplo, el de Patronio y el conde, y el del autor, que interfiere a su vez en el plano de la obra. Patronio actúa como bisagra entre la realidad del conde y la del cuento. Don Johan, como mediador entre el plano ficcional de la realidad del conde y la del lector. La validez de la enseñanza viene confirmada primero en el plano del conde, que «se falló por bien aconsejado del consejo de Patronio, su consejero, et fízolo commo él le consejara, et fallóse ende bien»; y luego en el del autor: «Et entendiendo do Johán que estos exiemplos eran muy buenos». Como señala Varvaro, la parte narrativa no se limita al cuento, sino que sus términos se reproducen en la vivencia personal del conde Lucanor:

Da ciò risulta perché il conte e Patronio non diano vita ad una cornice narrativamente valida. Essa infatti sarebbe in contrasto con la loro funzione specifica, che è quella di generalizzare la morale del racconto, perchè un maggiore rilievo narrativo presupporrebbe un più precisa caratterizzazione del loro piano e quindi inevitabilmente una maggior distanza dal lettore [...]. La cornice va misurata in termini non estetici ma strutturali e sotto questo aspetto essa è perfettamente adeguata al compito che l'autore le ha assegnato ${ }^{31}$.

Este marco narrativo, la austera lección que el conde recibe de su ayo Patronio, no puede compararse, como subrayaba Menéndez Pelayo, con el del Decameron, una auténtica fiesta para los sentidos y la imaginación ${ }^{32}$. La específica función didáctica cognitiva no podía permitirlo. La realidad, tal como la entiende don Juan Manuel, es mutable y que por lo tanto también deben serlo las normas de conducta de sus personajes. Por eso rompe la univocidad del exemplum mediante la profundización psicológica de los personajes y la generalización de la enseñanza a través de la abstracción de su práctica validez. ${ }^{33}$

${ }^{30}$ Ibidem, p. 225.

${ }^{31}$ Alberto Varvaro, «La cornice del Conde Lucanor», en Il racconto, ed. de M. Picone, Bologna, Il Mulino, 1985, p. 236.

${ }^{32}$ Marcelino Menéndez Pelayo, Orígenes de la novela, Madrid, 1905, p. XC.

${ }^{33}$ Salvatore Battaglia, «Dall'esempio alla novella», en Filologia Romanza, VII (1960), pp. 21-84. 
El salto con respecto a la cuentística anterior es insalvable, pero ya no podía seguir más adelante, en aras precisamente de su vocación didáctica ${ }^{34}$.

La finalidad primigenia es la completa comprensión de su texto. Y a ella se subordina todo el sistema compositivo, la estructura general de la obra y la particular de cada uno de los ejemplos. No todos ellos cumplen la misma función en este sentido. Hay un orden general, de acuerdo con la evolución del carácter de los temas de que progresivamente se irá encargando Patronio ${ }^{35}$, pero el «exemplo» primero, el último, y el que ocupa el lugar central -y hay que insistir de nuevo en la implicación directa de este orden en el proceso cognitivo-, cumplen claramente una marcada función estructural a través de la cual don Juan Manuel expone el tema fundamental de su obra.

El procedimiento no es exclusivo del autor ni de este texto concreto. También Boccaccio se sirve del mismo procedimiento compositivo. El Decameron, como El conde Lucanor, no es una simple recopilación de relatos sino «la formulazione di una complessa teoria del racconto» ${ }^{36}$. Su exposición programática queda especificada, también de manera significativa de acuerdo con el proceso cognitivo de la obra como ocurre en El conde Lucanor, en el Proemio, la Introduzione a la IV Giornata y en la Conclusione dell'autore, en los que el autor expresa una formulación de su teoría del relato breve ${ }^{37}$. Un planteamiento crítico que también hay que extender, como hace Picone, al «cuento $»^{38} \mathrm{de}$ Filippo Balducci, incluido en esta misma Introducción, como una «parabola del buon novellare ${ }^{39}$. Y lo mismo sucede con la novella de madonna Oretta (VI, 1), la «novella» que significativamente ocupa el lugar central de la obra, un viaje metaliterario que, desde esta misma consideración teórica, constituye también una auténtica formulación de la teoría de la narración ${ }^{40}$.

${ }^{34}$ Vid. Alberto Varvaro, ob. cit., p. 238.

${ }^{35}$ Sobre la ordenación de los «exemplos» en los distintos manuscritos vid. D. Devoto, Introducción al estudio de don Juan Manuel y en particular de "El conde Lucanor": una bibliografia, Madrid, Castalia, 1972, pp. 296-297.

${ }^{36}$ Michelangelo Picone, «Autore/narratori», en Lessico critico decameroniano, ed. de Bragantini, Renzo y Pier Massimo Forni, Torino, Bollati Boringhieri, 1995, pp. 34-59. Es la tesis mantenida entre otros por autores como Sanguineti ( GGli 'shemata' del Decameron», en Studi di filologia e letteratura, dedicati a Vincenzo Pernicone, Genova, Università degli Studi di Genova, 1975, pp. 141-153) o De Meijer («Le trasformazioni del racconto nel Decameron», en Atti del Convegno di Nimega sul Boccaccio, Pàtron, 1976, pp. 279-300).

${ }^{37}$ Vid. J. Paredes, «De las "formas simples" a la novella: Boccaccio o la teoría del relato breve», en Medioevo Romanzo, 30 (2006), pp. 310-322.

${ }^{38}$ «Non una novella intera, acciò che non paia che io voglia le mie novelle con quelle di così laudevole compagnia $[\ldots]$ mescolare».

${ }^{39}$ M. A. Picone, Autore/narratori, art. cit., p. 47.

${ }^{40}$ J. Paredes, «El viaje como estructura metanarrativa: la novella de Madonna Oretta (Dec.VI, 1)», en Actas del XI Congreso Internacional de la Asociación Hispánica de Literatura Medieval, ed. de A. López Castro y Luzdivina Cuesta Torre, Universidad de León, 2007, pp. 939-940; íd., «Parodia metali- 
De la misma manera, don Juan Manuel expone su teoría sobre el papel fundamental del consejero de nobles, presente en toda la obra ${ }^{41}$, a través del viaje ejemplar, que recorre todo el texto, desde los programáticos primer y último ejemplos, con la marcada incidencia también del relato central ${ }^{42}$. Pero, como señala Gómez Redondo, estos tres «exemplos» no bastan para definir la medida trama general que articula el conjunto a través de una serie, también perfectamente establecida de acuerdo con este proceso cognitivo, de bloques de diez en diez «exemplos» que corresponden a otros tantos grupos temáticos dedicados a la «elección del buen consejero», el «examen de las relaciones entre consejero y aconsejado», la «transformación del aconsejado en consejero», la «definición del aristocratismo consiliario» y la «configuración espiritual del consejo» ${ }^{43}$.

Este proceso cognitivo a través de la memoria está presente en todo el libro, pues «sería marabilla si de cualquier cosa que acaezca a cualquier omne, non fallare en este libro su semejança que acaesció a otro» (11). La obligada «semejança» implica el proceso cognitivo que la memoria actualiza y que, a veces, cumple en el texto una función de referencia intertextual. Es lo que ocurre, por ejemplo, en el «exemplo» tercero, «Del salto que fizo el rey Richalte de Inglaterra en la mar contra los moros», donde la solicitud de consejo por parte del conde Lucanor viene de inmediato acompañada por la referencia que Patronio hace al «exemplo» primero, con el que mantiene una continuidad estructural ${ }^{44}$, que el lector tiene obligadamente que recordar, en el que el rey sometía a una prueba a su privado para conocer su fidelidad:

Et pues este bien et este mal tan grande non se cobra sinon por las obras, ruégovos que, segund el estado que yo tengo, que cuydedes et me consejedes la manera mejor que entendiéredes por que pueda fazer emienda a Dios de los yerros que contra El fiz et pueda aver la su gracia.

- Señor conde Lucanor -dixo Patronio-, mucho me plaze de todas estas razones que avedes dicho, et señaladamente porque me dixiestes que en todo

teraria y teoría de los géneros. La poética de la novella», en Parodia y debate metaliterarios en la Edad Media, ed. de Mercedes Brea, Esther Corral Díaz y Miguel A. Pousada Cruz, Alessandria, Edizioni dell'Orso, 2013, pp. 55-67.

${ }^{41}$ Como acertadamente señala F. Gómez Redondo, El conde Lucanor es «un manual centrado en la figura del consejero y en el valor que los consejos deben tener por sí mismos» (ob. cit., p. 1160).

${ }^{42}$ Vid. J. Paredes, ««Et fuesse para la Tierra Sancta de Ultramar”. En torno a la estructura de los exemplos de El conde Lucanor», en Lectures de El Conde Lucanor de Don Juan Manuel, ed. de César García de Lucas y Alexandra Oddo, Presses universitaires de Rennes, 2014, pp. 145-164; íd., «Fuesse paral Papa et contol la sua fazienda. La escritura ejemplar del viaje en el Conde Lucanor», en Studia Hispánica Medievalia, X, vol. I, Letras, 71, 2015 (en prensa).

${ }^{43}$ F. Gómez Redondo, ob. cit., pp. 1163-1179.

${ }^{44} \mathrm{Vid}$. Serés, ed. cit., p. 32. 
esto vos consejase segund el estado que vós tenedes, ca si de otra guisa me lo dixiéredes, bien cuydaria que lo dixiéredes por me provar segund la prueva que el rey fezo a su privado que vos conté el otro día en el exiemplo que vos dixe (33-34).

Como señala María Rosa Lida, el «exemplo» se aparta de su sentido ascético original, relativo a la posibilidad de salvación de cualquier pecador por una sola buena acción, para destacar el servicio caballeresco a Dios: la salvación del alma según el estado a que se pertenezca, preocupación central de don Juan Manuel sobre la que gira todo el cuento, como con clara intención mnemotécnica subrayan los «viessos»:

Qui por cavallero se toviere, más deve desear este salto que non si en la orden se metiere o se encerrasse tras muro alto (38).

Aunque, como la propia autora matiza, en el manuscrito $\mathrm{H}$ de la Academia de la Historia encontramos una variante en el último verso, "encerrarse en muro alto", que no se compadece con el sentido del relato ${ }^{45}$, claramente especificado en el plano extradiegético del autor.

El mismo «exemplo» del raposo y el cuervo sería impensable sin esta consideración del proceso cognitivo de la memoria, pues todo el cúmulo de alabanzas que el raposo dirige tan intencionadamente a «Don Cuervo» para finalmente hacerle cantar y que deje caer el queso, y que dieron lugar al estudio comparativo que Menéndez Pidal realizaba con la versión del Arcipreste de $\mathrm{Hita}^{46}$, está basado en la rememoración precisa de la imagen previa establecida:

-Don Cuervo, muy gran tienpo ha que oy fablar de vós et de la vuestra nobleza et de la vuestra apostura. Et commo quiera que vos mucho busqué, non fue la voluntat de Dios nin la mi ventura que vos pudiesse fallar fasta agora; et agora que vos veo, entiendo que ha mucho más bien en vós de cuanto me dizían. Et por que veades que non vos lo digo por lesonja, tan bien commo vos diré las aposturas que en vós entiendo, tan bien vos diré las cosas en que las gentes tienen que non sodes tan apuesto (42).

${ }^{45}$ M. ${ }^{a}$ Rosa Lida de Malkiel, «Tres notas sobre don Juan Manuel», en Estudios de literatura española y comparada, Buenos Aires, 1966, p. 98.

${ }^{46}$ Vid. R. Menéndez Pidal, «Notas sobre una fábula de don Juan Manuel y del Arcipreste de Hita», en Hommage a Ernest Martinenche, Paris, 1938, pp. 183-186. 
En el «exemplo» IX, «De lo que contesció a los dos cavallos con el león», la rememoración de un hecho histórico: la estancia de don Enrique, hermano de Alfonso X y tío de don Juan Manuel, de quien se cuenta un lance con unos leones, que figura en la Crónica de los reyes de Castilla, sirve para dar verosimilitud a un relato ejemplar, la amistad de dos animales para vencer a un enemigo más fuerte que ellos, que figura en numerosos ejemplarios ${ }^{47}$. El hecho además puede contener, como señala Serés, un elemento autobiográfico: el "enemigo" del conde, es decir de don Juan Manuel, pudiera ser Alfonso XI, y el "otro omne muy más poderoso", el sultán de Marruecos, y el "grand daño", el sitio de Gibraltar ${ }^{48}$. El consejo final de Patronio, acorde con esta realidad, está basado en la capacidad de olvidar que tiene el enemigo del conde, cosa que al parecer no se produjo:

-Et vós, señor conde Lucanor, si entendedes que aquel vuestro enemigo ha tan grand recelo de aquel otro de que se recela et ha tan grand mester a vós, por que forçadamente aya de olvidar cuanto mal passó entre vós et él et entiende que sin vós non se puede bien defender, tengo que assí commo los cavallos se fueron poco a poco ayuntando en uno fasta que perdieron el recelo et fueron bien seguros el uno del otro, que assí devedés vós, poco a poco, tomar fiança et afazimiento con aquel vuestro enernigo [...] Pero si vierdes que aquel vuestro enemigo es tal o de tal manera, que [...] non quiso olvidar el mal talante que vos avía et entendiestes que vos lo tenía guardado para cuando viesse su tiempo que vos lo podría fazer, bien entendedes vós que non vos dexa logar para fazer ninguna cosa por que salga por vós de aquel grand peliglo en que está (53).

Toda la trama del cuento de don Yllán y el deán de Santiago, «De lo que contesció a un deán de Santiago con don Yllán, el grand maestro de Toledo», gira en torno a un tema muy extendido en los ejemplarios medievales como es el de la ingratitud del discípulo, que ha alcanzado una alta posición, pues «los omnes que grant estado tienen, de que todo lo suyo han librado a su voluntad, olvidan mucho aýna lo que otrie ha fecho por ellos» (58), con su maestro, unido al de la ilusión mágica ${ }^{49}$ :

${ }^{47} \mathrm{El}$ motivo aparece en las Gesta romanorum y en la Summa praedicantium de Bromyard, que lo toma a su vez de una anécdota de las Estratagemas de Frontino (Juan Manuel. El libro de los Enxiemplos del Conde Lucanor et de Patronio, ed. De Hermann Knust. Herausgegeben von Adolf Birch-HirsehfeldLeipzig. Dr. Seele Co., 1900).

${ }^{48}$ Serés, ed. cit., p. 50.

${ }^{49}$ Ambos temas aparecen en el Speculum morale de Vicente de Beauvais o las Anécdotes historiques de É. de Bourbon y en la Scala coeli, la Summa praedicantium de Bromyard, o el Promptuarium exemplorum de Hérolt, respectivamente. 
Et don Ylián se començó a quexar mucho, retrayéndol cuantas cosas le prometiera et que nunca le avía conplido ninguna et diziéndol que aquello recelava en la primera vegada que con él fablara, et pues aquel estado era llegado et nol cunplía lo quel prometiera, que ya non le fincava logar en que atendiesse dél bien ninguno (61).

Dicho lo cual, por arte de magia, se halló el Papa en Toledo, nuevamente deán de Santiago y don Yllán dispuesto a no compartir las perdices, con quien tan ingratamente había olvidado cumplir las promesas que en los sucesivos viajes fantásticos de su ascensión al poder había ido olvidando cumplir.

El «exemplo» XVI gira en torno al tema de la fama, que no es sino una recreación de la memoria, a través de una anécdota, recogida en la Primera Crónica General y en el Poema de Fernán González, en la que el autor realiza una modificación de "vierbo antigo»: «Murió el omne et murió el su nombre», que significativamente aparece con una formulación en sentido contrario: «Murió el omne, mas non murió el su nombre», expresión de la fama alcanzable «si quisiéremos olvidar los vicios et fazer mucho por nos defender et levar nuestra onra adelante» (76) Y así lo especifica el consejo de Patronio al conde: «Et vós, señor conde, pues sabedes que avedes a morir, por el mi consejo, nunca por vicio nin por folgura dexaredes de fazer tales cosas por que, aun desque vos murierdes, siempre finque viva la fama de los vuestros fechos» (76-77). Y el propio autor en sus «viessos»:

Si por vicio el por folgura

la buena fama perdemos,

la vida muy poco dura,

denostados fincaremos (77).

Sobre el mismo tema, una de las preocupaciones constantes de don Juan Manuel, trata el «exemplo» XLVI en el que, para aconsejar al conde sobre cómo acrecentar, llevar adelante y guardar la fama, «una de las cosas del mundo por que omne más debe trabajar», Patronio cuenta «lo que contesció a un philósopho que por ocasión entró en una calle do moravan malas mujeres». Para no terminar mal enfamado, como el filósofo del cuento, que no mantuvo el cuidado suficiente para guardar su fama, el conde debe hacer tres cosas: realizar buenas obras, pedir a Dios que siempre lo guíe para hacer aquello que acrecienten su fama, y «por fecho, nin por dicho, nin por semejança» nunca hacer nada porque la gente pueda tomar sospecha. Así lo concreta el autor en el refrán final: 
Faz sienpre bien et guárdate de sospecha, et siempre será la tu fama derecha (195).

El «exemplo» XLI, «De lo que contesció a un rey de Córdova quel dizían Alhaquem», es utilizado por don Juan Manuel para insistir en esa preocupación sobre la fama y la necesidad de que los «grandes omes» emprendan empresas dignas de su estado y condición para incrementar su prestigio y dejar memoria de sus hechos, que constituye además uno de los temas centrales del libro. La anécdota está referida a Al-Haham II al-Mustansir, califa de Córdoba (961-976), que terminó la mezquita, mandada construir por Abderramán $\mathrm{I}^{50}$. De la misma manera que el rey del cuento es recordado por este hecho: «Este es el añadimiento de Alhaquem», también el conde debe emprender «buenos fechos» para dejar memoria de ellos:

Et vós, señor conde, si tomades pesar o cuydades que vos loan por vos escarnecer del añadimiento que fiziestes en los capiellos et en las pihuelas et en las otras cosas de caça que vos fiziestes, guisad de fazer algunos fechos grandes et buenos et nobles, cuales pertenecen de fazer a los grandes omnes. Et por fuerça las gentes avrán de loar los vuestros buenos fechos, así commo loan agora por escarnio el añadimiento que fiziestes en las cosas de la caça (172).

Aunque no como motivo central, el tema vuelve a ser tratado en el «exemplo» XXVIII, en este caso, como especifica la moraleja: «Muchas cosas parescen sin razón, / et qui las sabe en sí, buenas son» (134), con un matiz de signo contrario, ya que aconseja sobre la conveniencia de no juzgar a nadie por la fama que le precede. Nuevamente don Juan Manuel se sirve de un personaje histórico, don Lorenzo Suárez Gallinato, al que coloca en el marco de una anécdota ficticia, uno de los ejemplos tradicionales sobre milagros que aparece en colecciones como las de Jacques de Vitry, Étienne. de Bourbon o San Bernardino de Siena. El personaje en cuestión, desterrado por Fernando III con el que finalmente se reconcilió, se acogió a la hospitalidad del emir de Granada, al que sirvió lealmente. La circunstancia histórica es aprovechada para insertar el milagro de la hostia profanada, aplicada al protagonista que, precisamente "membrándose cómo era cristiano", mata al clérigo renegado que realizaba la profanación.

Basada también en un personaje histórico, Muhamrnad ibn ai-Mutámid Alallahi ibn Abbad, de Sevilla (1040-1095) y su esposa Ramayquía,

${ }^{50}$ Vid. Pascual Gayangos, Prosistas anteriores al siglo XV, Madrid, Ribadeneyra, 1869, BAE, t. 51, p. XX. González Palencia (El conde Lucanor, Zaragoza, Clásicos Ebro, n $n^{\circ} 6,1956$, p. 88) dice que puede leerse en al-Makkarí, pero ninguno de los investigadores posteriores ha encontrado la anécdota. 
Rumayqiya, por ser esclava de Rumaiq, y después I'timad ar-Rumayquiya, el «exemplo» XXX recrea una bellísima anécdota recogida en los Analectas de Al-Makkarís1, que don Juan Manuel utiliza para ilustrar otra de sus preocupaciones principales: la necesidad de salvaguardar el bien individual contra la ingratitud y la frivolidad ajenas: «Qui te desconosce tu bien feccho, / non dexes por él tu grand provecho» (139). Y es nuevamente el tema de la memoria, en este caso el olvido, el que articula todo el relato, perfectamente construido para preparar el desenlace con una pregunta irónica final que constituye el motivo central del cuento. De la misma manera que el rey Abenabet del cuento recrimina a Rumayquiya haber olvidado cómo por ella había hecho poner almendros por toda la sierra de Córdoba para que pareciera que estaba nevada, y llenar una gran albufera de agua de rosas, y en lugar de tierra poner azúcar, canela, nardos, almizcle, ámbar y todas las buenas especias, y caña de azúcar en lugar de paja, para que pudiera hacer cuantos adobes quisiera, también el conde debe dejar de hacer lo que el ingrato amigo le pide:

Et vós, señor conde, si veedes que por cosa que por aquel omne fagades, que si non le fazedes todo lo ál que vos dize, que luego olvida et desgradesce todo lo que por el avedes fecho, consejo·vos que non fagades por él tanto que se vos torne en grand daño de vuestra fazienda. Et a vós otrosí conséjovos que si alguno fiziesse por vós alguna cosa que vos cunpla et después non fiziere todo lo que vós querríedes, que por esso nunca lo desconozcades el bien que vos vino de lo que por vós fizo (139).

El "exemplo" XLV, «De lo que contesció a un omne que se fizo amigo et vasallo del Diablo», es uno de tantos relatos sobre pactos diabólicos que pululan por los ejemplarios ${ }^{52}$. El tema, de larga tradición en la literatura española donde generalmente figura como el "milagro de Teófilo" 53 , adquiere en don Juan Manuel una originalidad y carácter particulares por la manera en que se estructura el cuento. También aquí la memoria juega un papel fundamental en la articulación del relato a través de la figura del diablo, cuya cualidad esencial es precisamente la capacidad de conocer todas las cosas pasadas y en la rememoración final de las figura de Alvar Núñez y Garcylasso ${ }^{54}$, «que fueron

${ }^{51}$ P. Gayangos, The History of the Mohammedan Dynasties in Spain, Londres, 1843: Dozy, Historia de los musulmanes en España, Madrid, 1920.

${ }^{52}$ El motivo aparece en la Summa praedicantium de Bromyard, el Speculum laicorum de John de Hoveden o los Sermones de Jacques de Vitry, entre otras muchas colecciones.

${ }^{53}$ Milagros de Nuestra Señora (XXIV), Cantigas de Santa María (III), Castigos y documentos (cap. LXXXII), etc. También el Arcipreste de Hita realizó una recreación del tema en el Libro del buen amor (1453-1484).

${ }^{54}$ Vid. Crónica de Alfonso XI, cap. LXI. 
los omnes del mundo que más fiaron en agüeros et en estas tales cosas», y que por ello tuvieron tan mal fin.

****

El procedimiento se convierte así en un motivo recurrente en toda la obra, prueba de la particular dedicación de un autor que, rompiendo los límites entre realidad y ficción, está presente en su propio texto a través de una estructura que trasluce sus preocupaciones y su doctrina. Esta particular intencionalidad didáctica cognitiva, más patente en el plano extradiegético donde el autor, en una estructura cíclica de espejos, se proyecta en sus personajes y en la temática de los propios cuentos, determina la composición del texto entero y de cada uno de los relatos. La distancia del exemplum al Libro de los exemplos, viene marcada por esta preocupación artística y doctrinal capaz de vivificar una estructura en la que don Juan Manuel se identifica con el conde Lucanor y este con sus personajes, para al final ser identificado por los propios lectores, que también asumen la enseñanza de los cuentos. Las palabras «falagueras et apuestas» con que don Juan Manuel pretende atrapar la atención de los lectores para que lean y guarden en la memoria «las cosas aprovechosas que son ý mezcladas» encuentran su eco paralelo en el «exemplo» XXI donde, como en un intento de volver a la función cognitiva expresada al principio, el aconsejado se vuelve a su vez consejero. Todo un símbolo de la clara intencionalidad del autor:

Et vós, señor conde, pues criastes este moço et querríades que se enderesçasse su fazienda, catad alguna manera que por exienplos o por palabras maestradas et falagueras le fagades entender su fazienda (93).

Recibido: $15 / 05 / 2015$

Aceptado: 30/05/2015 


\title{
(2)
}

\section{LA MEMORIA LiteraRia. MeCANISMOS ALEGÓRICOS Y COGNITIVOS EN LA CUENTÍSTICA MEDIEVAL (DEL EXEMPLUM AL CONDE LUCANOR)}

\begin{abstract}
RESUMEN: La memoria es utilizada como proceso de alegorización y mecanismo cognitivo en el exemplum, poniendo de manifiesto los resortes del ars praedicandi y su uso como medio de aprendizaje. El recurso, ampliamente utilizado en todos estos relatos tan directamente vinculados a la homilética, alcanza también una enorme difusión en las colecciones de cuentos más directamente relacionadas con la función didáctica, donde los mecanismos cognitivos, siempre con una clara intención ejemplar, tienen una relevancia particular. La obra prototípica es El conde Lucanor, donde la intención didáctica, translación del pensamiento y la propia doctrina del autor, determinan la estructura y el sentido profundo del texto. El proceso cognitivo a través de la memoria está presente en todo el libro, y de manera particular en el plano extradiegético donde el autor se proyecta en sus personajes y en la temática de los propios cuentos. La distancia del exemplum al Libro de los exemplos viene marcada por esta preocupación artística y doctrinal, capaz de vivificar una estructura en la que don Juan Manuel se identifica con el conde Lucanor y este con sus personajes, para al final ser identificado por los propios lectores, que también asumen la enseñanza de los cuentos.
\end{abstract}

Palabras claves: Memoria literaria. Conde Lucanor. Exemplum. Mecanismos cognitivos en el Conde Lucanor. Proceso de alegorización en el exemplum.

The Literary MEMory. Allegorical and COGNITIVE MECHANISMS IN MEDIEVAL STORY-TELLING (FROM THE EXEMPLUM TO CONDE LUCANOR)

ABSTRACT: Memory is used as an allegory creating process as well as a cognitive mechanism in the exemplum, thus revealing the resources of the ars praedicandi and its implementation as a method of learning. Such resources, greatly used by these stories directly connected to the homily genre, reached a widespread use in story collections bearing an apparent didactic function where cognitive mechanisms achieve a special relevance while purporting a clearly exemplary intention. In this sense, the typical work is undoubtedly El Conde Lucanor, where the didactic intention, a faithful translation of the thought and credo of the author himself, determines the structure and the deep meaning of the text. The cognitive process assigned to memory stands out throughout the whole book, particularly in the 'extradiegetic' level where the author's mind is reflected in his characters no less than in the very topics dealt with in the stories. The distance between the exemplum to the Libro de los ejemplos is determined by the cited artistic and moral concern, which enables the creation of a structure where Don Juan Manuel is identified himself with count 


\section{Juan PARedes}

Lucanor and the latter in turn with his characters, himself to be identified in the last instance by the readers who also assume the moral lessons implied in the stories.

Keywords: Literary memory. Conde Lucanor. Exemplum. Cognitive mechanisms in Conde Lucanor stories. Allegory creating process in the exemplum. 